\title{
Wilckodontics: The Periodontal Orthodontics
}

\author{
Ritunja Singh ${ }^{1}$ Shilpa Chourasia ${ }^{1}$ Palak Sharma ${ }^{1}$ Soumya Gupta ${ }^{2}$ Gangesh B. Singh ${ }^{3}$ \\ Ankita Srivastava ${ }^{1}$
}

${ }^{1}$ Department of Periodontology and Oral Implantology, New Horizon Dental College and Research Institute, Bilaspur, Chhattisgarh, India

${ }^{2}$ Department of Orthodontics, Rungta College of Dental Science and Research Institute, Bhilai, Chhattisgarh, India

${ }^{3}$ Department of Orthodontics, Govt Dental College, Raipur, Chhattisgarh, India

\begin{abstract}
Address for correspondence Ritunja Singh, Department of Periodontology and Oral Implantology, New Horizon Dental College and Research Institute, Bilaspur 495001, Chhattisgarh, India (e-mail: ritunja21@gmail.com).
\end{abstract}

Dent J Adv Stud 2018;6:53-56

\begin{abstract}
Keywords

- corticotomy

- tissue engineering

- Wilckodontics

Periodontally accelerated osteogenic orthodontics (PAOO), also known as Wilckodontics, is a clinical procedure that combines corticotomy (a surgical technique in which the bone is cut, perforated, or mechanically altered), particulate bone grafting, and orthodontic force application. By this procedure, the teeth can be made to move through the bone rapidly by means of harnessing and stimulating the innate potential of the bone and utilizing tissue engineering principles. Once the tooth movement gets completed, bone rebuilds around the tooth, thereby reducing the time of orthodontic treatment from years to months. This article aims to present a comprehensive review about PAOO or Wilckodontics.
\end{abstract}

\section{Introduction}

The term Wilckodontics or periodontally accelerated osteogenic orthodontics (PAOO) describes a classic relationship between orthodontic and periodontic specialties by which orthodontic tooth movement can synchronize with tissue engineering principle of periodontal regenerative surgery to

- move the teeth rapidly through the bone ${ }^{1}$;

- reduce appliance-associated discomfort;

- and increase stability through the creation of novel local osseous phenotype. ${ }^{2}$

In this procedure, surgical trauma triggers the release of inflammatory mediator leading to vasodilation of blood vessels and increasing the recruitment of osteoclasts at surgical sites.

This in turn accelerates bone remodeling, whereas, on the other hand, corticotomy decreases the bone mineral density, thereby decreasing the resistance of dentoalveolar tissues to orthodontic forces and increased risk of root resorption. ${ }^{3}$

\section{Historical Background}

The concept of corticotomy-facilitated tooth movement was first described in 1893, by L. C. Bryan, which was then published in textbook by Guillford. ${ }^{4}$ In 1959, Henrich Kole said that the resistance to tooth movement was caused by the thickness and continuity of the cortical bone. This led to the invention of "bony block movement" in which he stated that by disrupting the continuity of the cortical bone, it was possible to move the blocks of bone in which the teeth were embedded.

In 1975, Duker studied the effect of corticotomy on the tooth, vitality, and concluded that the marginal bone must be preserved and interdental cuts should be made $2 \mathrm{~mm}$ apical to level of alveolar crest. ${ }^{5}$ This technique was then modified by Wilcko et al, in which they included alveolar augmentation along with corticotomy assisted orthodontic tooth movement by using combination of de-mineralized freeze dried bone allograft (DFDBA)/xenograft/absorbable allograft and named it as PAOO. ${ }^{6}$

\section{Criteria for Patient Selection}

- Class 1 malocclusion with moderate to severe crowding or constricted maxilla.

- Severe bimaxillary protrusion.

- Mild class III malocclusion.

- Class II malocclusion requiring expansion.

- Molar uprighting.

- Facilitate eruption of impacted teeth.

(C)2018 Bhojia Dental College and

License terms Hospital affiliated to Himachal Pradesh University 


\section{Contraindications}

- Patient having active periodontal disease.

- Severe class III cases.

- Patients having osteoporosis or other bone diseases.

- Patients under long-term medication such as steroids or nonsteroidal anti-inflammatory drugs (NSAIDs).

- Patients with systemic diseases.

\section{Technique of Periodontally Accelerated Osteogenic Orthodontics}

Following proper case selection and orthodontic bracket placement ( 1 week prior to the surgery), crevicular incision is given under local anesthesia, buccally and lingually extending at least up to two teeth beyond the primary area to be treated.?

\section{Flap}

Full-thickness flaps are carefully reflected in the coronal area both labially and lingually, whereas in the apical area, a partial-thickness flap is raised to allow flap mobility at the time of suture. In maxillary central incisor area, the interdental papilla is preserved for esthetics. Thorough debridement and curettage is done following the reflection of flap ( - Fig. $\mathbf{1}){ }^{8}$

\section{Decortication}

Alveolar bone activation is done with selective decortications using number 1 or 2 round bur or piezoelectric knife.

\section{Grooving}

Vertical grooves are placed in the interradicular spaces extending from 2 to $3 \mathrm{~mm}$ below the alveolar crest up to $2 \mathrm{~mm}$ beyond apices of the roots. A circular-shaped horizontal corticotomy then connects these vertical corticotomies ( - Fig. 2).

\section{Particulate Bone Grafting}

The activated bone is layered with particulate bone grafting material after bone activation. Clindamycin phosphate or bacteriostatic water solution of approximately $5 \mathrm{mg} / \mathrm{mL}$ or platelet-rich plasma is used to wet the particulate bone grafting material, which facilitates the ease of placement. ${ }^{9}$ DFDBA, autogenous bone, deproteinized bovine bone, or a combina-

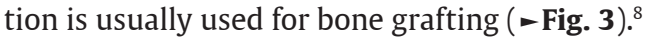

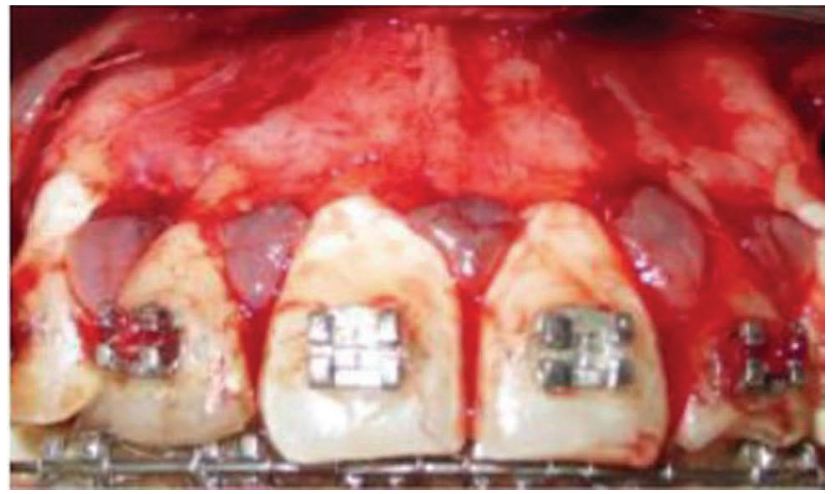

Fig. 1 Flap reflection.

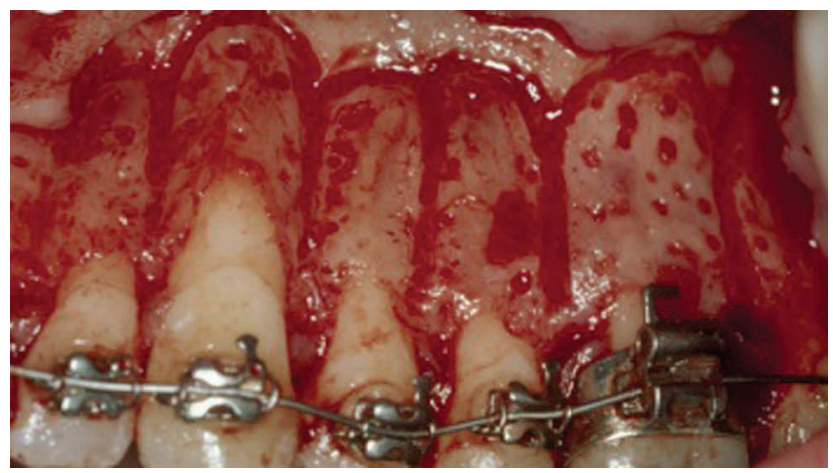

Fig. 2 Grooving and decortication.

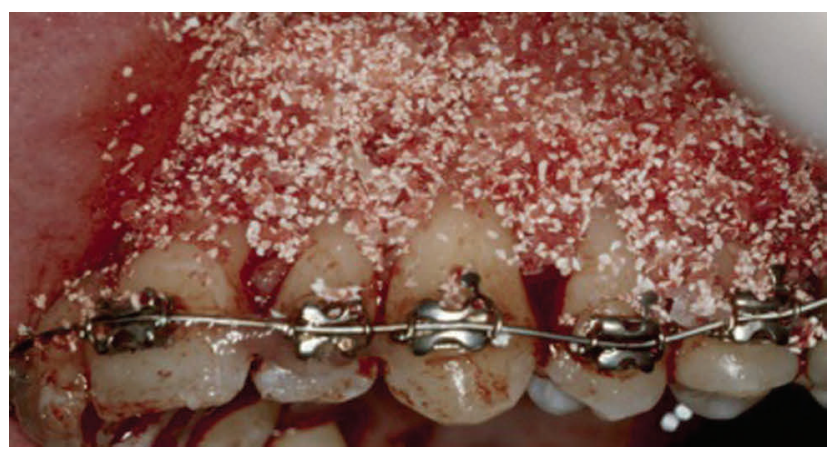

Fig. 3 Particulate bone grafting.

\section{Flap Closure}

Interrupted loop sutures are used to approximate the flaps with a nonresorbable material. Flap should be closed under minimal tension. A time period of 2 weeks is ideal for the epithelial attachment establishment, and suture is removed only after this time period ( - Fig. 4). ${ }^{10}$

Postsurgical management: Instructions are given for use of antibiotics, analgesics, mouthwash, and ice pack application (in case of postoperative swelling). ${ }^{10}$

\section{Orthodontic Adjustments}

Orthodontic treatment should be initiated immediately within 2 weeks, and a heavy orthodontic force must be applied on the teeth following flap repositioning. ${ }^{10}$

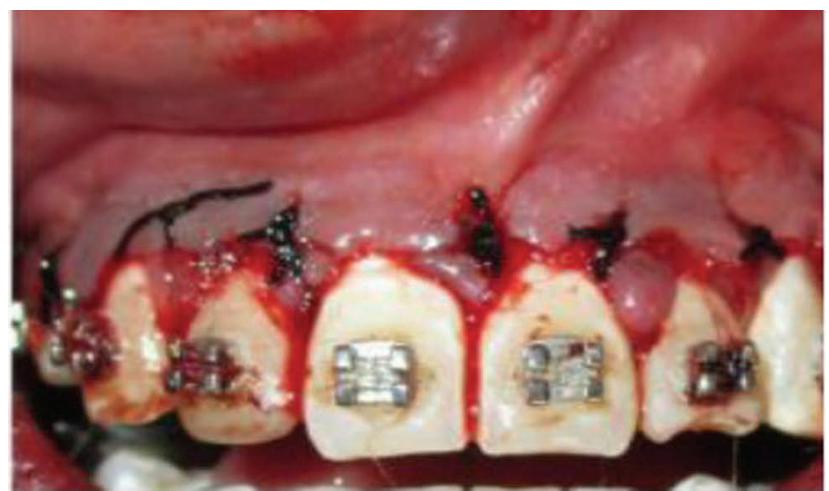

Fig. 4 Flap closure. 


\section{Review of Literature}

In 2001, Wilcko et al analyzed two cases and demonstrated that this method offers short treatment times, has the ability to simultaneously reshape, and increases the buccolingual thickness of the supporting bone. ${ }^{11}$

In 2013 Guiol et al performed a surgical technique for maxillary autobone grafting complementary and simultaneously to Le Fort 1 orthognathic surgery. Their results showed improved and uneventful healing without any excess morbidity. ${ }^{12}$

In 2015, Tan et al presented a case report of two patients with severe bimaxillary protrusion. The mean retraction rate was $1.24 \mathrm{~mm} / \mathrm{mo}$ for the first case and $1.212 \mathrm{~mm} / \mathrm{mo}$ for second case by using this procedure. Hence they concluded that Wilckodontics is a viable treatment option for quick results. ${ }^{13}$

In 2016, Cheung et al evaluate mini implant facilitated micro-osteo-perforation (MOPs) in rats. They found that mini implant facilitated MOPs accelerated tooth movement without any increased risk of root resorption. ${ }^{14}$

In 2018, Viwattanatipa and Charnchairerk performed a systematic review to evaluate the effectiveness of corticotomy and piezocision in canine retraction. They concluded that this procedure resulted in higher level of patient satisfaction and treatment outcomes (-Figs. 5, 6). ${ }^{15}$

\section{Advantages}

1. Acceleration in tooth movement, decrease in treatment time, and less chances of relapse.

2. Less chances of root resorption.

3. Materials such as metal, gold or ceramic brackets can be used.

4. Because the tooth movement occurs through softened bone, there is less discomfort to the patient.

\section{Disadvantages}

1. More expensive than functional braces.

2. Additional surgery is required.

3. Increase in the possibility of pain, swelling, and infection following surgery.

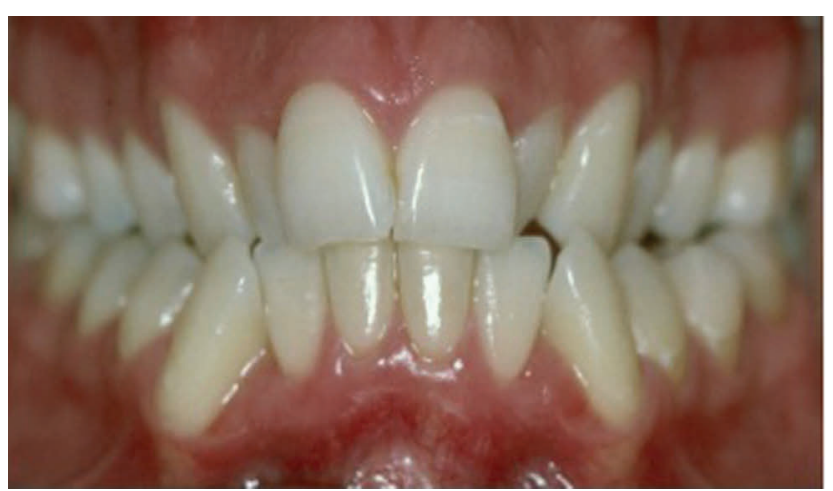

Fig. 5 Before-PAOO procedure for class 1 malocclusion with moderate to severe crowding or constricted maxilla. PAOO, periodontally accelerated osteogenic orthodontics.

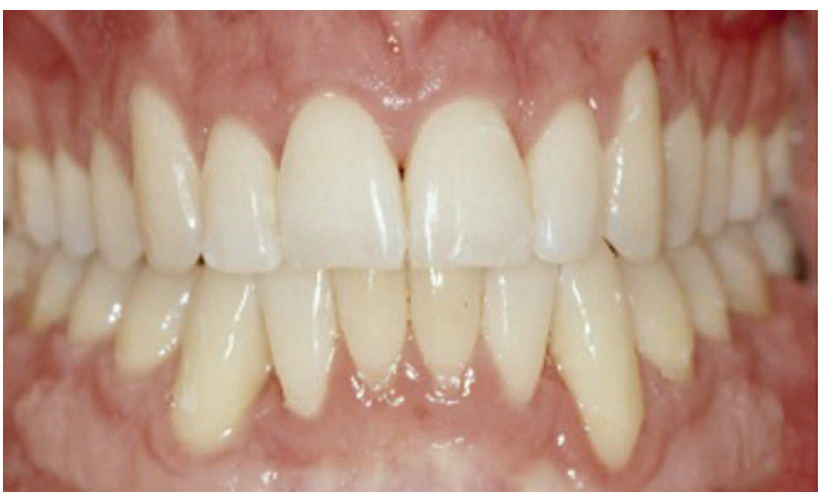

Fig. 6 After-PAOO procedure. PAOO, periodontally accelerated osteogenic orthodontics.

\section{Advances}

Laser: Laser-assisted corticotomy is considered as useful procedure as it is noninvasive. It uses the erbium, chromium-doped yttrium scandium gallium garnet (Er-Cr-YSGG) laser radiation for reduction in the cortical bone without flap reflection, thereby minimizing needs of surgical intervention. ${ }^{5}$

\section{Monocortical Tooth Dislocation and Ligament Distraction Technique}

Monocortical tooth dislocation and ligament distraction (MTDLD) technique is a combination of two different dental movements that work separately at the same time on two opposite root surfaces. Both vertical and horizontal microsurgical corticotomies are performed to eliminate the cortical bone resistance with peizosurgical microsaw. This is followed by immediate application of strong biomechanical forces, which causes rapid dislocation of the roots and bone together. ${ }^{6}$

\section{Conclusion}

PAOO is an interdisciplinary treatment modality involving orthodontic as well as periodontic treatment approaches. It aims at reducing the treatment time and risks of root resorption. Traditional orthodontic treatment aims only at tooth movement consuming a lot of time. Combining this orthodontic tooth movement with periodontal surgeries facilitated faster treatment results. Assessment of the treatment quality, however, still remains point of concern by many authors. More clinical research is required to evaluate long-term effectiveness of this technique.

\section{Conflict of Interest}

None declared.

\section{References}

1 K S, M S, D R, Gowd P. Wilckodontics-a novel synergy in time to save time. J Clin Diagn Res 2014;8(1):322-325

2 Murphy $\mathrm{CN}$. In vivo tissue engineering for orthodontists: a modest first step. In: Davidovitch Z, Mah J, Suthanarak S, eds. Biological Mechanism of Tooth Eruption, Resorption and 
Movement. Boston, MA: Harvard Society for the Advancement of Orthodontics; 2006:385-410

3 Mostafa MM. Developing a Corticopuncture System to Accelerate the Rate of Tooth Movement. UCLA Electronic Theses and Dissertations. Los Angeles, CA: University of California; 2014

4 Guillford SH. Orthodontia: Or Malposition of Human Teeth, Its Prevention and Remedy. Philadelphia, PA: Spangler and Davis; 1893

5 Khurana R, Kudva PB, et al. Wilckodontics-a gift of time. EC Dent Sci 2016;4(5):869-873

6 Vercellotti T, Podesta A. Orthognathic microsurgery: a new surgically guided technique for dental movement. Int J Periodont Restorat Dent 2007;27:325-331

7 Srinivasan S, Vijay VK, Ramaprabha G. Periodontally Accelerated Osteogenic Orthodontics-An overview. Int J Engineer Sci Res 2(1):51-57

8 Mehta S, Mohan P, et al. Wilckodontics: a multidisciplinary treatment approach in dentistry-a review. World J Pharm Sci 2017;6(10):386-395

9 Wilcko MT, Wilcko WM, Pulver JJ, Bissada NF, Bouquot JE. Accelerated osteogenic orthodontics technique: a 1-stage surgically facilitated rapid orthodontic technique with alveolar augmentation. J Oral Maxillofac Surg 2009;67(10):2149-2159
10 Hwei PC, Thomas JT. Role of periodontal therapy in rapid tooth movement. J Dent Med Sci 2014;13(2):62-65

11 Wilcko WM, Wilcko T, Bouquot JE, Ferguson DJ. Rapid orthodontics with alveolar reshaping: two case reports of decrowding. Int J Periodontics Restorative Dent 2001; 21(1):9-19

12 Guiol J, Stephen S, Jean D. Autografting Le Fort I, 21st ICOMS. Abstracts Oral Papers 2013;xx:1329-1330

13 Tan FHK, Chhatrala RC, Chatterjee A, Shrikant S, Garla V. Accelerated orthodontics: case report. Int J Contemp Med Res 2015;2(2):1329

14 Cheung T, Park J, Lee D, et al. Ability of mini-implant-facilitated micro-osteoperforations to accelerate tooth movement in rats. Am J Orthod Dentofacial Orthop 2016;150(6):958-967

15 Viwattanatipa N, Charnchairerk S. The effectiveness of corticotomy and piezocision on canine retraction: a systematic review. Korean J Orthod 2018;48(3):200-211 